\title{
La protección de datos personales en la jurisprudencia del Tribunal Constitucional de Chile
}

\author{
Data Protection in the Jurisprudence of Chile's Constitutional \\ Court
}

FLAVIO QUEZADA RODRÍGUEZ

Facultad de Derecho, Universidad de Valparaíso

\begin{abstract}
RESUMEN En el presente trabajo se sistematiza y analiza críticamente la jurisprudencia del Tribunal Constitucional de Chile sobre la protección de datos personales. En virtud de ello, se periodiza su jurisprudencia en dos etapas: la primera, en la cual no se asume la relevancia constitucional de la protección de datos personales y, una segunda, en la cual sí lo hace. Se parte el análisis haciendo una breve referencia al fundamento que dota de relevancia genuinamente constitucional a este tema. A juicio del autor, ello estará en dos puntos: en su exigencia desde la perspectiva de los derechos fundamentales y, por otra parte, como necesidad para la limitación del poder estatal. La primera etapa jurisprudencial se caracteriza por un desarrollo de problemas típicos de la protección de datos personales, sin hacer un análisis diferenciado de la garantía constitucional de protección a la vida privada. La segunda, por su parte, se caracterizará por problematizar diferenciadamente la protección de datos personales de la protección a la vida privada, en el contexto de su anclaje constitucional en ésta última garantía. Por último, se sintetizan conclusiones que se derivan del análisis realizado
\end{abstract}


PALABRAS CLAVe Protección de datos personales, derechos fundamentales, derecho a la vida privada, jurisprudencia constitucional, Tribunal Constitucional chileno.

ABSTRACT This paper systematize and critically analyzes the jurisprudence of the Constitutional Court of Chile on the protection of personal data. To fulfill that purpose, order chronologically its cases in two stages: the first, in which assumes no constitutional significance of the protection of personal data and, second, in which it does. The analysis starts with a brief reference to the foundation that gives genuinely constitutional relevance to this topic. To the author, it will be in two points: in its demand from the perspective of fundamental rights and, moreover, as a necessity for the limitation of the state power. The first stage is characterized by a jurisprudential development of typical problems on the protection of personal data, without making a separate analysis of the constitutional guarantee of privacy protection. The second, meanwhile, will be characterized by distinctly analyze the problematic of the protection of personal data privacy protection, in the context of his constitutional basis. Finally, it summarize conclusions derived from analysis.

KEYWORDS Protection of personal data, fundamental rights, the right to privacy, constitutional jurisprudence, the Constitutional Court of Chile.

El presente trabajo tiene por objetivo analizar críticamente la jurisprudencia constitucional sobre la protección de datos personales, para lo cual es necesario sistematizar, en lo posible, los pronunciamientos del Tribunal Constitucional (en adelante, «el Tribunal» o «TC») en la materia, para luego desentrañar los estándares mínimos que, a juicio de dicho Tribunal, ha de respetar el legislador al regular dicha protección.

Para ello, se analizarán críticamente los principales fallos en la materia, exponiendo, de modo sintético, los argumentos de los votos de mayoría y sólo destacando las innovaciones que, en el transcurso del tiempo, va incorporando cada uno de ellos.

Se exponen, primeramente, los fundamentos que convierten a la protección de datos personales en un problema genuinamente constitucional que exige un adecuado tratamiento dogmático y jurisprudencial. 


\section{LA RELEVANCIA PROPIAMENTE CONSTITUCIONAL DE LA PROTECCIÓN DE DATOS}

La doctrina ha reconocido que el desarrollo de las nuevas tecnologías y, en especial, la informática, traen aparejado problemáticas nuevas de relevancia constitucional, en concreto, en la protección a los ámbitos más internos del desarrollo humano. Pero, como señalara Pérez Luño, el punto más acuciante que suscita la protección de la intimidad ${ }^{1}$ frente a la informática no es tanto el impedir el progreso electrónico de informaciones, que son necesarias para el funcionamiento de cualquier Estado moderno, sino el asegurar un uso democrático de la tecnología informática (I979: 68).

Tan cierta es la utilidad de estas tecnologías para que cualquier gobierno moderno pueda cumplir sus fines, como el peligro que entraña el uso indebido o abusivo de la tecnología informática por parte del Ejecutivo o de determinados grupos privados que "amenazaría de muerte el desarrollo de las instituciones democráticas», centrándose, entonces, el problema jurídico en los mecanismos de control social de aquella realidad (Pérez Luño, I979).

Este problema es propiamente constitucional en un doble sentido. Primero, en las sociedades desarrolladas científica y técnicamente las insospechadas posibilidades de reunir, almacenar, relacionar y transmitir todo tipo de información permite que bien los poderes públicos, bien los sujetos privados, puedan tener conocimiento de amplias parcelas de nuestras vidas y puedan utilizar dicha información para su beneficio causándonos (no necesariamente) notorios daños (Murillo de la Cueva, I979: 37), con lo cual se imponen nuevos retos al entendimiento del ámbito normativo de los derechos fundamentales.

I. Se debe reparar que los propios términos de la Constitución Política exigen cuidado en la importación de desarrollo doctrinal y jurisprudencial comparado. En efecto, se tuvo presente que, si bien el principal desarrollo de la materia se ha dado en base a dos paradigmas generales de protección constitucional de datos personales —el norteamericano y el europeo (en especial, Alemania y España)—, la Constitución Política se diferencia profundamente de ellos. En efecto, mientras en Chile se protege explícitamente la vida privada, en Estados Unidos su protección ha sido una construcción doctrinal y jurisprudencial; por otro lado, mientras en España y Portugal sus constituciones se refieren expresamente a la informática dando lugar a la protección de datos personales como un derecho fundamental diferenciado de la intimidad o privacidad, la nuestra omite el punto. 
Segundo, por cuanto la información es poder (Pérez Luño, I979: 68) y, más aún, si ella permite conocer e influir en el actuar más íntimo de los ciudadanos, la concentración de estas tecnologías en el aparato estatal imponen nuevos desafíos a la tarea propia del constitucionalismo: la limitación del poder. De esta forma, es un elemento constitutivo de la forma de gobierno misma, por cuanto coadyuva no sólo a la configuración de la identidad individual sino también a la conformación social (Saldaña, 2007: IOI). ${ }^{2}$

Estos dos aspectos son lo que la doctrina comparada ha denominado problemas estructurales (Solove, 2006: 487) y que constituyen los fundamentos que convierten a la protección de datos en un problema genuinamente constitucional: atañe a la esfera más íntima del ser humano al ser una expresión de la privacidad y por cuanto mediante su consagración y efectivo respeto es posible concebir una sociedad como democrática (Saarenpää, 2003: ı6).

De este modo, estos problemas estructurales exigen un adecuado desarrollo y anclaje constitucional de la protección de datos personales. Para poder analizar si el Tribunal Constitucional ha sido capaz de asumir en plenitud esta situación, se pasará a exponer sus criterios para luego analizaros desde una óptica crítica.

\section{ESTÁNDARES CONSTITUCIONALES EN LA JURISPRUDENCIA DEL TRIBUNAL CONSTITUCIONAL}

El Tribunal en varias ocasiones se ha pronunciado respecto al derecho configurado por el artículo i9 nro. 4 de la Constitución Política y, en dos recientes fallos, incluye en su análisis la problemática de la protección de datos personales. De este modo es posible plantear la existencia de dos etapas jurisprudenciales en la materia según si se reconoce o no la relevancia constitucional de la protección de datos personales, en otros términos, si entiende que la protección de los datos personales es un mandato de protección al Estado de rango constitucional y, a su vez, si constituye también posiciones subjetivas de protección constitucional. Esto último habría acontecido recién el 20 I I con dos sentencias, sin embargo,

2. Cf. lo señalado por Nogueira: «El derecho al respeto de la vida privada de las personas tiene, además de su naturaleza de derecho de defensa, el de garantía institucional del pluralismo y del sistema democrático» (2005: 45I). 
este gran avance se ve fuertemente ensombrecido por el pobre desarrollo de nuestra jurisprudencia constitucional en la materia.

A continuación se expondrá un análisis de las dos etapas jurisprudenciales que ha desarrollado el Tribunal Constitucional.

\section{PRIMERA ETAPA: AUSENCIA DE LA PROTECCIÓN DE DATOS PERSONALES COMO PROBLEMA CONSTITUCIONAL}

Como ya se explicó, la protección de datos personales es un problema genuinamente constitucional, pero ello no fue dilucidado por el Tribunal sino hasta muy tardíamente, sin hacer eco de lo planteado en otras latitudes. Esta primera etapa se caracteriza por un desarrollo de problemas típicos de protección de datos personales a la luz de la garantía de protección de la vida privada o intimidad.

El primer fallo a destacar es el rol nro. I98-94, dictado con fecha 4 de enero de 1995 , cuya importancia radica principalmente en que se trata del primer pronunciamiento respecto a la garantía de toda persona al «respeto y protección a la vida privada y a la honra de la persona y su familia», ${ }^{3}$ el cual si bien se trataba de un caso directamente relacionado con la protección de datos personales, no se reparó en esta peculiaridad o especial ámbito de protección de la vida privada.

Cabe destacar que, como será en lo sucesivo, se trata como términos sinónimos «intimidad» $\mathrm{y}$ "privacidad».

En dicha ocasión declaró que es inconstitucional no proteger el goce efectivo de los derechos y libertades que la Constitución asegura y garantiza a todas las personas (entre ellas el derecho a la intimidad personal y de la familia) al dotar al Consejo de Defensa del Estado de facultades absolutamente discrecionales para la investigación de determinado delito, como las de recoger e incautar documentos o antecedentes probatorios de cualquier naturaleza, pertenecientes a personas objeto de una investigación de dicho servicio, o para requerir a terceros la entrega de antecedentes o documentos sobre cuentas corrientes bancarias, depósitos u otras operaciones sujetas a secreto o reserva pertenecientes también a las personas investigadas. ${ }^{4}$

3. Artículo ig nro. 4 de la Constitución Política.

4. En efecto, el TC señala: «el referido inciso tercero del artículo I6 del proyecto 
La razón de la vulneración al artículo is nro. 4 de la Constitución estaría, entonces, en la falta de regulación en forma «íntegra, completa y exacta» del procedimiento y los casos en que ha de aplicarse dicha facultad, por cuanto el artículo analizado se refería sólo a situaciones «absolutamente discrecionales». ${ }^{5}$

Este es el inicio de la construcción del principio de legalidad en la protección de datos personales, el cual exige, a lo menos, que de otorgarse facultades a algún organismo público para restringir la privacidad, debe establecerse un procedimiento regulado en forma íntegra, completa y exacta en la ley, como también, la existencia y procedencia del ejercicio de la potestad reglamentaria de forma restrictiva.

Dado que no es tema de este trabajo, baste con señalar que tan es-

vulnera la Constitución al no proteger el goce efectivo de los derechos y libertades que la Carta asegura y garantiza a todas las personas, cuando dota a un servicio público, Consejo de Defensa del Estado, de facultades absolutamente discrecionales, como las de recoger e incautar documentos o antecedentes probatorios de cualquier naturaleza pertenecientes a personas objeto de una investigación de dicho servicio, o para requerir a terceros la entrega de antecedentes o documentos sobre cuentas corrientes bancarias, depósitos u otras operaciones sujetas a secreto o reserva pertenecientes también a las personas investigadas. Las facultades conferidas se ejercen por el servicio sin contemplar su sometimiento a control o aprobación judicial previa alguna, pues no se preveen recursos especiales u ordinarios que permitan una revisión de lo actuado o decretado por una instancia superior, con lo cual, salvo el ejercicio de acciones constitucionales, dejan en indefensión a las personas naturales o jurídicas que directa o indirectamente se puedan ver involucradas con una investigación como la que se autoriza al Consejo de Defensa del Estado en el proyecto de ley en examen» (considerando décimo).

5. En palabras del TC, como señala: «Infringe también la disposición en análisis la garantía que contempla el nro. 5 del artículo I9 de la Constitución, que establece conjuntamente con el nro. 4 , lo que la doctrina ha denominado el derecho a la intimidad de que gozan las personas y su familia.

«En efecto, tal como se ha señalado en la letra b) precedente, el inciso tercero del artículo I 6 en examen, no contempla en forma íntegra, completa y exacta el procedimiento ni los casos precisos como debe aplicarse, pues se refiere a situaciones absolutamente discrecionales, en las que deben actuar los funcionarios del servicio autorizado para recoger e incautar la documentación y los antecedentes probatorios y objetos que estimen necesarios para la investigación. Es decir, al no especificarse el procedimiento y no señalarse los casos precisos en que las medidas proceden, se está vulnerando la inviolabilidad de las comunicaciones y documentos privados, que sólo pueden interceptarse, abrirse o registrarse en los casos y formas determinadas por la ley» (considerando décimo). 
tricto parámetro de legalidad es difícilmente conciliable con la potestad reglamentaria de ejecución, la cual, según las reglas generales (ante la ausencia de disposición especial) ha de tener aplicación en la materia. ${ }^{6}$ Por lo mismo, ya posteriormente se verá atemperado y enriquecido con la aplicación de los criterios de proporcionalidad.

La siguiente sentencia a destacar es el rol nro. 389-03, de fecha 28 de octubre de 2003. Su relevancia está dada por el desarrollo de elementos de la privacidad directamente aplicables a la materia de protección de datos, no obstante en ningún momento se refiera, en específico, a esta problemática. En ella se concluye que atribuir a una entidad administrativa (Unidad de Análisis Financiero) la facultad de solicitar información sin limitación alguna violentaría el derecho a la privacidad y dignidad humana. Para arribar a dicha conclusión se realiza un análisis del contenido del artículo I9 nro. 4 de la Constitución, señalándose aspectos de gran relevancia:

I. La dignidad humana tiene una relación sustancial, clara y directa con la privacidad (de la persona y su familia), la que, al ser un derecho que emana de aquélla, implica que aquél merece un «reconocimiento y protección excepcionalmente categóricos». Es lo que llamaremos el fundamento en la primacía axiológica del ser humano ${ }^{7}$ de la protección de datos personales. ${ }^{8}$

6. Ver sobre esta materia: Cordero (2009) y Zúñiga (200I).

7. La primacía jurídico-constitucional de la persona humana (positivación de la primacía axiológica del ser humano) es el elemento estructurante de nuestra forma de Estado. Esto es, la primacía de la persona como valor, o sea, del valor de la persona, y, por tanto de todas sus específicas y diversas identidades, así como de la variedad y pluralidad de los puntos de vista externos (ético-político) expresados por ellas. En términos positivos, la dignidad de las personas con que parte su enunciado el primer artículo de nuestra Constitución, implica que será el Estado, en tanto creación humana, el que deberá estar a nuestro servicio y no al revés; esto es plenamente coherente con entender a Chile como una República democrática (y no totalitaria o autoritaria). Por lo mismo, no es de extrañar que tan pronto se declara la dignidad de las personas, se señale en el mismo artículo que el Estado estará al servicio de la persona humana.

La primacía axiológica del ser humano es el valor sobre el que se basa la moderna tolerancia: que consiste en el respeto de todas las posibles identidades personales y de todos los correspondientes puntos de vista, es permitir a todos y todas la posibilidad de su mayor realización espiritual y material posible, en los términos del artículo I inciso 3. (Ferrajoli, 200I: 905-908).

8. El TC lo señala en los siguientes términos: «además y como consecuencia de lo 
2. Se señala que a dicho "ámbito reservado de la vida» no es lícito penetrar sin el consentimiento del afectado, de un lado, o por decisión de autoridad fundada en una ley dictada conforme a la Constitución. De este modo, se reconoce el principio del consentimiento. ${ }^{9}$

Este punto no ha sido lo suficientemente rescatado por la propia jurisprudencia del Tribunal Constitucional, por cuanto constituye un elemento del contenido esencial mismo del derecho, como también se reconoce en el derecho comparado (Serrano, 2005: 255). De esta manera, respecto de los datos personales, serán el consentimiento y la habilitación legal los títulos que justificarán su tratamiento (Murillo de la Cueva, 2007: 20).

3. Se señalan los sujetos obligados a la protección a que hace referencia el artículo I9 nro. 4 de la Constitución: el legislador, las demás autoridades y los particulares (ya en sus conductas o sus estipulaciones privadas). Con lo cual se establece el efecto horizontal de la vida privada vinculando no sólo a los poderes públicos, sino también a los privados. ${ }^{10}$

4. El respeto y protección de la dignidad y de los derechos a la priva-

recién expuesto, la Carta Fundamental asegura a todas las personas, sin distinción ni exclusión alguna, en su artículo I9 nro. 4 inciso primero, "El respeto y protección a la vida privada y pública y a la honra de la persona y de su familia”. En tal sentido considera esta Magistratura necesario realzar la relación sustancial, clara y directa, que existe entre la dignidad de la persona, por una parte, y su proyección inmediata en la vida privada de ella y de su familia, por otra». Más adelante, profundizando en el punto, establece: «la privacidad, en los variados rubros descritos, integra los derechos personalísimos o del patrimonio moral de cada individuo, los cuales emanan de la dignidad personal, como se ha dicho, y son, por su cualidad de íntimos de cada sujeto, los más cercanos o próximos a esta característica, única y distintiva, del ser humano. Por tal razón, ellos merecen reconocimiento y protección excepcionalmente categóricos tanto por la ley, como por los actos de autoridad y las conductas de particulares o las estipulaciones celebradas entre éstos» (considerando décimoctavo).

9. En efecto, así lo señala el TC: «su proyección inmediata en la vida privada de ella y de su familia, por otra, circunstancia que vuelve indispensable cautelar, mediante el respeto y la protección debidas, ese ámbito reservado de la vida, en el cual no es lícito penetrar sin el consentimiento del afectado, de un lado, o por decisión de la autoridad fundada en la ley que hubiere sido dictada con sujeción a la Constitución, de otro» (considerando decimooctavo).

Io. De esta manera el TC adopta el paradigma germano en esta materia. Con todo, debe prevenirse que existen posiciones críticas ante la irrelevancia constitucional de los poderes privados en esta materia en la doctrina norteamericana (Cate y Litan, 200I). 
cidad y de la inviolabilidad de las comunicaciones, son base esencial del desarrollo libre de la personalidad de cada sujeto, así como de su manifestación en la comunidad a través de los grupos intermedios autónomos con que se estructura la sociedad. ${ }^{11}$

5. El ámbito de autonomía previamente desarrollado es también sustento del sistema de instituciones vigente en nuestro país. ${ }^{12}$

Las dos ideas anteriores permiten entender la vida privada como un derecho de libertad positiva o de autonomía, en el sentido que no implica solamente un ámbito de no interferencia estatal, sino de autodeterminación individual conforme a los propios postulados tanto en la organización de la vida personal como familiar (Romero, 2008: 219).

6. La vida privada es un derecho no absoluto que puede ser limitado, respetando los márgenes constitucionales, en especial, el contenido esencial del derecho. ${ }^{13}$

El tercer fallo relevante es el rol nro. 52 I-06, dictado con fecha I de agosto de 2006. En él se reitera, en lo medular, la doctrina de la sentencia antes sintetizada, ${ }^{14}$ estableciéndose la inconstitucionalidad de un

I I. En los propios términos del TC: «el respeto y protección de la dignidad y de los derechos a la privacidad de la vida y de las comunicaciones, son base esencial del desarrollo libre de la personalidad de cada sujeto, así como de su manifestación en la comunidad a través de los grupos intermedios autónomos con que se estructura la sociedad. En ligamen con lo que viene de ser expuesto, menester resulta recordar que tal autonomía es también sustento del sistema de instituciones vigente en nuestro país, debiendo a su respecto cumplirse la exigencia de respeto, especialmente cuidadoso, que se ha destacado ya con relación a la dignidad de la persona humana» (considerando veintiuno).

I2. Ver cita anterior.

I3. El TC lo expresa con los siguientes términos: «el ejercicio del derecho a la vida privada y a la protección de las comunicaciones de igual naturaleza no es, obviamente, de sentido y alcance absoluto, debiendo ser reconocido, por consiguiente, que el legislador, dentro de los límites y para las finalidades previstas en la Constitución, especialmente en los preceptos fundamentales de ella ya transcritos en la presente sentencia, está habilitado en orden a dictar las normas que regulen su ejercicio para que sea legítimo» (considerando veintidós).

I4. El TC señala expresamente que reiterará la doctrina de la sentencia rol nro. 38903: «en relación con la norma transcrita en el considerando precedente resulta necesario reiterar la doctrina sentada por este Tribunal en sentencia de 28 de octubre de 2003 (rol nro. 389), con ocasión del examen preventivo de constitucionalidad del proyecto de ley que creó la Unidad de Análisis Financiero y modificó el Código Penal en materia de lavado y blanqueo de activos» (considerando diecisiete). 
precepto legal que disponía que, para otorgar la autorización para que la Unidad de Análisis Financiero requiriera antecedentes amparados por el secreto o reserva, el ministro respectivo resolvería de inmediato. Se decidió así, por cuanto se sostuvo que no sería posible la dedicación y reflexión necesarias ante un asunto de naturaleza así de delicada. ${ }^{15}$

La cuarta sentencia constitutiva de esta etapa es el rol nro. I365-09, dictada con fecha 8 de abril de 20 Io. En este fallo se analiza la constitucionalidad de la toma de muestras biológicas de forma forzada a una persona condenada para extraer su huella genética e incorporarla al Sistema Nacional de Registros de ADN. Si bien la materia objeto de análisis de constitucionalidad permitía un desarrollo profundo de la protección de datos personales (en su subcategoría de datos sensibles), el Tribunal no utiliza la oportunidad y siendo lacónico en la materia, señala su constitucionalidad, principalmente, por las siguientes razones:

- Se trata de un registro de ADN no codificante, esto es, que no permite revelar ni indagar en otras características de la personalidad — distintas de la identidad_ o de la ascendencia de la persona afectada. ${ }^{16}$

I 5. En los términos del TC: «al disponer el proyecto de ley en examen que tratándose de la autorización previa de un ministro de Corte de Apelaciones de Santiago para que la Unidad de Análisis Financiero requiera antecedentes amparados por el secreto o reserva, o que provengan de personas no contempladas en el artículo 3 de la ley I9.9 I3, "El ministro resolverá de inmediato", se configura una situación que se opone a la dedicación y reflexión indispensables que un asunto de naturaleza tan delicada y compleja, como es autorizar una excepción a la reserva o al secreto de determinados antecedentes, amerita por parte del órgano que ha de cumplir el control heterónomo fundamental para asegurar el debido resguardo de los derechos involucrados» (considerando veintidós).

I6. Mientras realiza el juicio de razonabilidad de la limitación a los derechos fundamentales del caso, señala: «dicho cuerpo legal precisa que la huella genética alude sólo al registro alfanumérico personal elaborado exclusivamente sobre la base de información genética que sea polimórfica en la población, carezca de asociación directa en la expresión de genes y aporte sólo información identificatoria (artículo I, inciso segundo). Se trata, por ende, de una limitación legítima de la privacidad constituida por lo que la ciencia asocia a la obtención del «ADN no codificante», que no permite revelar ni indagar otras características de la personalidad — distintas de la identidad- o de la ascendencia de la persona afectada, lo que no ha sido desvirtuado en estos autos por evidencia que obligara a este Tribunal a concluir algo diferente» (considerando veintisiete). 
- Este registro sólo podría ser consultado por el Ministerio Público, los tribunales u organismos públicos a quienes ellos autoricen.

- Se imponía legalmente un deber de reserva sobre la información relacionada con los registros respectivos a toda persona que interviniera en su construcción y administración. ${ }^{17}$

- En síntesis, la privacidad estaría legítimamente limitada, por cuanto se afecta en forma precisa y determinada mediante una ley que persigue objetivos legítimos.

Este fallo, en virtud de sus razonamientos, constituye un nuevo desarrollo del principio de legalidad en la protección de datos personales, el cual exigiría el establecimiento en la ley tanto de las garantías adecuadas de protección del derecho, como las limitaciones mismas que han de ser precisas y determinadas en pos de un objetivo legítimo.

5. Por último, se señaló que no se afectaría la esencia del derecho a la privacidad, en la medida que la esfera íntima que toda persona desea resguardar de la injerencia de terceros no sufre ningún detrimento. ${ }^{18}$

Este planteamiento constituye un retroceso en la sustantivación del derecho que hiciera la sentencia rol nro. 389-03, por cuanto se le entiende como una típica libertad negativa en vez de un derecho-autonomía.

La siguiente sentencia es la rol nro. I683-10, dictada con fecha 04 de enero del 20 I. En ella se analiza la constitucionalidad de la sanción penal de relaciones homosexuales consentidas cuando el accedido carnalmente es un menor de edad. Si bien pudiera señalarse que este caso constituye un problema de vida privada de los que no dicen relación con

I7. Sobre el punto 2 y 3, el TC señaló: «el artículo 2 de la ley nro. I9.970 garantiza el carácter secreto del Sistema Nacional de Registros de ADN, en cuanto sólo puede ser consultado por el Ministerio Público y por los tribunales o por los órganos públicos a quienes ellos autoricen. El artículo I I, entre tanto, impone el deber de reserva sobre la información relacionada con los registros respectivos a toda persona que intervenga en la toma de muestras, obtención de evidencias y determinación de huellas genéticas» (considerando veintisiete).

I8. Respecto a los puntos 4 y 5, el TC señaló: «Puede afirmarse, entonces, que la privacidad de las personas condenadas, que se encuentran en los supuestos descritos por la ley nro. I9.970, se ve afectada, en forma precisa y determinada, y sólo en la medida que dicha afectación coadyuve al cumplimiento de los objetivos que persigue el legislador, según se profundizará más adelante» (considerando veintisiete). 
datos personales, es evidente que, al entenderse que esta materia tiene su anclaje constitucional en el artículo I 9 nro. 4 , los principios que para él se establezcan han de aplicarse al específico campo de la protección de datos personales.

En esta ocasión se advierten nuevos aspectos de la vida privada, señalándose:

I. Se permiten limitaciones al derecho a la privacidad en vista de la necesidad de proteger un bien jurídico superior. ${ }^{19}$

Esta afirmación, elemento basal de la decisión del caso, constituye su argumento más criticable: la existencia de un principio de no afectación a un bien jurídico superior. En efecto, la privacidad goza del máximo rango normativo, de manera que no puede existir un bien jurídico superior que la desplace por el sólo hecho de ser superior, sino que el problema ha de plantearse en términos ya de ponderación o de adecuada diferenciación estructural de los ámbitos normativos de los bienes constitucionales que, aparentemente, estuvieren en conflicto. En otros términos, dado el caso analizado, para determinar si existía o no aplicación de la protección a la vida privada debería haberse utilizado el denominado principio de lesividad: el derecho a la autodeterminación contenido en la protección a la vida privada no es un derecho absoluto, de manera que los actos que causan daño a otros no se encuentran constitucionalmente protegidos, incluso si ello constituye un elemento central de la identidad personal. ${ }^{20}$ De este modo, el problema no era de primacía de cierto bien constitucional sobre otro, sino de efectiva o no aplicación.

Por ello es correcto afirmar, como lo hace el Tribunal en dicha sentencia, que es lícita la intromisión a la privacidad en caso de realización de

I9. El TC señaló: «Que, en segundo lugar, se permiten limitaciones al derecho a la privacidad en vista de la necesidad de proteger un bien jurídico superior» (considerando cuarenta).

20. «El derecho a la autodeterminación no es absoluto, los actos que causan daño a los demás no están protegidos constitucionalmente, aunque sea central para la identidad de una persona». Este principio que halla sus antecedentes en el pensamiento de John Stuart Mill fue concebido originalmente como útil, desde un punto de vista práctico, para las decisiones legislativas y adjudicativas: «la sociedad puede legítimamente para regular la actividad que le afecta, y resguardar que los actos de definición individual no le afecten» (Rubenfeld, I989: 756; la traducción es nuestra). 
hechos delictivos, por cuanto ellos se caracterizan por constituir conductas dañosas socialmente.

2. Se delimita el alcance de la privacidad al concebirla, en síntesis, como una esfera de libertad de intromisiones de agentes externos y ajenos a la interioridad física o psicológica del sujeto y las relaciones que mantiene o tuvo con otros. ${ }^{21}$

En este punto se soslaya su pronunciamiento previo sobre la prometedora doctrina asentada en la segunda sentencia de esta etapa, consistente en entender la privacidad como un derecho de autonomía y no como una libertad negativa, por cuanto vuelve a concebirla en términos estrictamente negativos.

\section{SEGUNDA ETAPA: PROTECCIÓN DE DATOS PERSONALES COMO PROBLEMA CONSTITUCIONAL}

Esta segunda etapa se inicia el año $20 \mathrm{II}$, con dos sentencias que constituyen importantes avances en esta materia, por de pronto, el más importante lo constituye el hecho de problematizar constitucionalmente la protección de datos personales.

El sexto pronunciamiento jurisprudencial lo constituye la sentencia rol nro. I732-IO-INA y rol nro. I800-IO-INA (acumulados), de fecha 2 I de junio de 20 I r. En este caso se analizó la constitucionalidad del deber de transparencia activa de las empresas públicas, consistente en la publicación de las remuneraciones de sus ejecutivos. En síntesis, las innovaciones de este fallo son las siguientes:

I. Se expresa que la vida privada asegura a todas las personas el amparo de la injerencia de terceras personas, procurando así el pleno ejercicio de la libertad personal sin interferencias ni intromisiones o presiones

2I. Siguiendo doctrina nacional, señala: «el derecho a la privacidad, entendido por nuestro Constituyente como "la posición de una persona o entidad colectiva personal en virtud de la cual se encuentra libre de intromisiones o difusiones cognoscitivas de hechos que pertenecen a su interioridad corporal y psicológica o a las relaciones que ella mantiene o ha mantenido con otros, por parte de agentes externos que, sobre la base de una valoración media razonable, son ajenos al contenido y finalidad de dicha interioridad o relaciones" (Hernán Corral Talciani citado en Vivanco, 2006: 345), no puede ser concebido como un derecho absoluto, protegido contra cualquier tipo de limitación legal» (considerando trigésimo octavo). 
indebidas. De este modo, se sigue insistiendo en la cualidad eminentemente negativa de la protección de la vida privada. ${ }^{22}$

2. Se reconoce, por primera vez de manera expresa, que la protección de la vida privada de las personas guarda una estrecha relación con la protección de los datos personales, configurando lo que la doctrina denomina el derecho a la autodeterminación informativa. ${ }^{23}$

3. La autodeterminación informativa se traduce en el control de las personas sobre sus datos y comprende el derecho a saber sobre la existencia de ficheros o archivos de registro de información de carácter personal, públicos o privados, cuáles son sus finalidades y quiénes son los responsables de los mismos, de manera que las personas concernidas puedan conocer los datos propios contenidos en dichos archivos o ficheros, teniendo el derecho a actualizarlos o a solicitar mediante el recurso de habeas data su rectificación o cancelación. Se siguió en este punto los planteamientos del profesor Humberto Nogueira quien sostiene, entre nosotros, la doctrina desarrollada por los españoles Murillo de la Cueva y Pérez Luño y, muchos años antes, la jurisprudencia del Tribunal Constitucional Federal Alemán. ${ }^{24}$

Las dos ideas anteriores permiten afirmar que, por primera vez, se asume la protección de datos personales como un problema genuinamente constitucional, asentando su protección en el ámbito normativo de la vida privada.

A pesar del importante avance que significa lo anterior, se cae, acto

22. En efecto, textualmente señaló: «el artículo I9 nro. 4 de la Constitución, además del derecho al honor y a la honra, asegura a todas las personas el respeto y la protección de la vida privada, el cual debe quedar al amparo de la injerencia de terceras personas. La Constitución procura facilitar así el pleno ejercicio de la libertad personal sin interferencias ni intromisiones o presiones indebidas. Así lo establece claramente, por su parte, el artículo i i nro. 2, de la Convención Americana de Derechos Humanos: "Nadie puede ser objeto de injerencias arbitrarias o abusivas en su vida privada [...] Toda persona tiene derecho a la protección de la ley contra esas injerencias o esos ataques" " (considerando veintidós).

23. En los términos del TC: «la protección de la vida privada de las personas guarda una estrecha relación con la protección de los datos personales, configurando lo que la doctrina llama derecho a la autodeterminación informativa» (considerando veinticinco).

24. Ver considerando veinticinco. Sobre el punto en la jurisprudencia alemana, véase la Sentencia BVerfGE 65, I [Censo de Población] (Schwake, 2009: 94). 
seguido, en una gran inconsistencia, cual es la de entender en términos negativos la protección de la vida privada y, a la vez, un ámbito de su regulación como un derecho de autodeterminación. En otros términos, entender un mismo derecho como libertad negativa y positiva a la vez, sin reparar que ambas tipologías estructurales de derechos se refieren a ámbitos normativos incompatibles (Ferrajoli, 2007).

La «estrecha relación» entre vida privada y datos personales no es más que una relación de pertenencia: la protección de los segundos se ancla constitucionalmente en la protección de la primera.

4. Quedan fuera del ámbito protegido de la vida privada aquellos datos o aspectos que acarrean repercusiones para la ordenación de la vida social y pueden afectar derechos de terceros e intereses legítimos de la comunidad. ${ }^{25}$

Este punto es de relevancia, por cuanto, además de aceptar el principio de lesividad antes explicado, como elemento delimitador del contenido constitucional de la vida privada, da lugar (sin asidero positivo, ni una adecuada problematización) a un símil del principio conservador de «afectación al orden social como un todo» (Rubenfeld, I989: 759), esto es, la protección de la privacidad no abarcará a aquellos ámbitos que repercutan en la «ordenación de la vida social», la cual, en tanto elemento dado, congela una realidad social (moral) dada; límite que difiere del de «intereses legítimos de la sociedad» que permiten dotarlo de (la necesaria) plasticidad histórica.

De este modo, la vida privada, amparada constitucionalmente, se delimita en lo que llamaremos principio de no lesión de intereses sociales o derechos fundamentales. Dado el rango constitucional de la protección de datos personales, la delimitación que hagan los intereses sociales ha de ser amparada en normas de igual rango, por lo mismo, solo puede ser restringido o delimitado por derechos de igual jerarquía.

25. Textualmente señaló: «se encuentran fuera del ámbito protegido de la vida privada aquellos datos o aspectos que acarrean repercusiones para la ordenación de la vida social y pueden afectar derechos de terceros e intereses legítimos de la comunidad. Por eso la Ley de Protección de Datos Personales prescribe que éstos pueden ser recolectados, almacenados y difundidos por terceros cuando una ley lo autorice, lo que ocurre en diversos y múltiples ámbitos de nuestro ordenamiento jurídico, o previa aquiescencia de su titular. La sociedad actual no podría funcionar sin el tratamiento legal de los datos personales, que se ve facilitado por la aplicación de la informática» (considerando veintisiete). 
Por último, no parece razonable, ni se sigue argumentativamente, negar protección a cierta clase de datos personales per se, por cuanto esto debe ser resultado de una ponderación legislativa que limite el derecho.

5. Se reconoce que no todos los datos personales son sensibles (que requerirían mayor protección), pero ello no obsta que de igual manera se encuentren amparados por el derecho a la privacidad. ${ }^{26}$

El reconocimiento de la categoría de datos sensibles y su protección en el artículo I9 nro. 4 termina en construir el ámbito protector de dicha garantía constitucional, configurando la siguiente estructura:

RESPETO Y PROTECCIÓN A LA VIDA PRIVADA DE LA PERSONA Y SU FAMILIA

DATOS PERSONALES

DATOS SENSIBLES

De este modo, el respaldo constitucional de la protección de datos personales redunda en que los datos sensibles gozan de igual rango normativo en su amparo (se trata de una categoría de aquellos), pero que, atendido a que con ellos se agravan los problemas estructurales (la potencialidad lesiva del contenido esencial de la privacidad es mayor, tanto

26. Lo señaló en los siguientes términos: «el legislador, cuando ha señalado ámbitos esenciales de la esfera privada que se encuentran especialmente protegidos, ha definido la información relativa a los mismos como datos sensibles, que, conforme a la Ley de Protección de la Vida Privada, son "aquellos datos personales que se refieren a características físicas o morales de las personas o a los hechos o circunstancias de su vida privada o intimidad, tales como los hábitos personales, el origen racial, las ideologías y las opiniones políticas, las creencias y las convicciones religiosas, los estados de salud físicos o psíquicos y la vida sexual” (artículo 2, letra g, ley 19.628). Así, aquellas informaciones — según la ley - forman parte del núcleo esencial de la intimidad y su resguardo debe ser mayor. Una intromisión en ese ámbito, si no está bien regulada por la ley, puede lesionar la libertad del individuo en cualquiera de sus ámbitos: libertad de pensamiento, de expresión, ambulatoria, de asociación, etc. Pero incluso en esa esfera particularmente delicada, la ley puede autorizar un conocimiento parcial o completo de ciertos datos, como ocurre por ejemplo cuando está en juego la salud pública o en procesos de investigación o juzgamiento de delitos, en el marco de un justo y racional procedimiento» (considerando veintiocho). 
desde una perspectiva objetiva como subjetiva), el legislador ha de dotarlos de mayor protección para cumplir con el mandato constitucional de «protección» a la vida privada personal y de la familia.

El séptimo y último pronunciamiento está constituido por la sentencia rol nro. I 894-20II-CPR, de fecha I2 de julio de 20II. En esta ocasión se analiza la constitucionalidad de un registro privado a cargo de los dueños de instalaciones prestadoras de servicios de Internet (los denominados «cibercafés»). En esta sentencia se innova en varias ideas, a saber:

I. Dentro de los «muchos aspectos comprendidos dentro de este derecho» (artículo I9 nro. 4 de la Constitución) se encuentra el asegurar que nadie sea objeto de acechos, «cual si fuera un simple medio puesto a satisfacer los apetitos de los demás». ${ }^{27}$

2. La intimidad resultaría usurpada en casos de seguimientos o monitoreos sistemáticos, constantes y focalizados para husmear a qué lugares asiste alguien, por pertenecer «a una categoría a priori sospechable de ciudadanos». ${ }^{28}$

Estas dos ideas ponen el acento en un problema propio de la protección de la vida privada, pero que se materializa de una especial manera en la protección de datos personales, es la figura del acecho o monitoreo que, además de constituir una injerencia a la intimidad personal, confi-

27. En las palabras del TC: «entre otros muchos aspectos comprendidos dentro de este derecho, se encuentra el asegurar que nadie sea objeto de acechos, cual si fuera un simple medio puesto a satisfacer los apetitos de los demás» (considerando veinte).

28. Al respecto, el TC, textualmente, señaló: «naturalmente, cualquiera entiende —aun sin ser jurisperito- que está a salvo en su legítima discreción para circular anónima e indistinguiblemente de los demás, sin chequeos o registros, a menos que a juicio de una autoridad competente hubiera causas probables que inciten a pensar que se están perpetrando ilícitos concretos y verosímiles.

«De suerte que, esto sentado, dicha intimidad resultaría usurpada en caso de seguimientos o monitoreos sistemáticos, constantes y focalizados para husmear a qué lugares asiste alguien, por pertenecer a una categoría a priori sospechable de ciudadanos; por dónde - vías, caminos o canales - se desplaza en particular; cuál es el número de los sitios que visita y de las direcciones contactadas, precisamente; con quién, o con cuánta duración y frecuencia se producen las conexiones realizadas. Más todavía cuando, a partir de estos datos, hoy es factible ir de hurones e inferir historiales o perfiles individuales, que incluyen hábitos y patrones de conducta humana, hasta poder revelar las preferencias políticas, opciones comerciales e inclinaciones sociales de las personas» (considerando veintidós). 
gura uno de los mecanismos en virtud del cual agentes privados o públicos pueden hacerse de información personal. Pero dicha recolección de información no es inocua en la libertad positiva que constituye la privacidad (esfera de autodeterminación), por cuanto genera el llamado "efecto Panopticon», en referencia a la metáfora de Bentham, el que consiste en la autorrestricción o autocensura del sujeto monitoreado que le impide ejercer, efectivamente, su libertad (Solove, 2006: 49I-5).

Esta problemática no es aprehendida en su complejidad por el Tribunal, y no puede serlo, por cuanto problematizar aquello requiere conceptualizar previamente la protección a la vida privada en términos positivos, tarea que desde el 2003 ha abandonado (u olvidado) nuestro Tribunal.

No obstante lo anterior, es posible determinar la existencia del estándar de interdicción de seguimientos o monitoreos sistemáticos, constantes y focalizados.

3. Se reconoce que la extensión del derecho al respeto y protección de la vida privada puede abarcar muchas situaciones, no cerrándose a un posterior desarrollo más acabado de él, pero se señala, a la vez que, a lo menos, comprendería un ámbito de no intromisión en un aspecto reservado de la vida personal, que cierra paso a las indagaciones de otros, sean agentes estatales o privados. ${ }^{29}$

De este modo, si bien se vuelve a reiterar la doctrina de la privacidad/ libertad-negativa, se deja abierta la posibilidad de ampliar el contendido de esta garantía constitucional.

4. El problema del monitoreo se ve agravado por cuanto mediante el tratamiento de datos personales es posible «revelar las preferencias políticas, opciones comerciales e inclinaciones sociales de las personas». ${ }^{30}$

Se reconoce así la relevancia constitucional del tratamiento de datos

29. Se señaló: «sin pretender extenderse ahora a todos los contornos que presenta el referido derecho, ni querer agotar todas las situaciones que podrían lesionarlo, es lo cierto que éste comprende un ámbito de no intromisión en un aspecto reservado de la vida personal, que cierra el paso a las indagaciones de otros, sean agentes estatales o privados» (considerando veintiuno).

30. Ver nota 29. Respecto a las «opciones comerciales», se debe reparar que, si bien no constituyen per se datos sensibles, el conocimiento y/o tratamiento de aquellas opciones revelan datos de aquel tipo, por cuanto saber cuáles son las preferencias de consumo o hábitos en este punto dicen tanto o más que otros hechos respecto a las personas. 
sensibles, el cual, independientemente de ser automatizado o manual, tiene mayor potencialidad lesiva.

En este punto se trata muy superficialmente, por parte del Tribunal, dos aspectos de relevancia: el dinámico tratamiento de datos que exige, para la adecuada protección de la vida privada, un entendimiento positivo de esta garantía; y la revelación de datos verdaderos o correctos que, además de vulnerar el control de la propia información, aumenta el riesgo de lesiones a otros bienes constitucionales (principalmente, el principio de no discriminación).

5. La intimidad no sólo puede darse en los lugares más recónditos, sino que también se extiende, en algunas circunstancias, a determinados espacios públicos donde se ejecutan específicos actos con la inequívoca voluntad de sustraerlos de la observación ajena. ${ }^{31}$ Este sería el caso de los cibercafés e Internet.

De este modo, es irrelevante, para efectos de determinar la protección de la vida privada, la cualidad del ámbito espacial de desarrollo de la actividad libre amparada por el derecho.

Esta expresión de la protección a la vida privada sólo puede entenderse en su sentido positivo, por cuanto el fundamento de dicha ampliación de protección se halla en el mismo efecto de autocensura («efecto Panopticon») que antes se explicara. Ésta es otra inconsistencia en la jurisprudencia del Tribunal Constitucional.

6. Deben establecerse garantías de protección adecuadas o suficientes para resguardar la vida privada, las que deben ser establecidas legalmente, siendo inconstitucional una remisión global en blanco al reglamento. ${ }^{32}$

3 I. El TC señaló: «la intimidad no sólo puede darse en los lugares más recónditos, sino que también se extiende, en algunas circunstancias, a determinados espacios públicos donde se ejecutan específicos actos con la inequívoca voluntad de sustraerlos a la observación ajena (Novoa Monreal, I98I: 5 I y 202-204; y también Barros Bourie, I 998: 47)» (considerando veintitrés).

32. Sobre este punto, el TC estableció: «sin reparar que se impone un sistema de control cuyo peso recae en entidades privadas ajenas a lo policial, el proyecto, puesto a impedir que se produzcan filtraciones o se trafique con la información contenida en dichos registros ad hoc, personalísima y valiosa, establece un deber de reserva, que resulta insuficiente para resguardar el derecho de que se trata, tal como se ha indicado precedentemente. 
En este razonamiento, además de la reiteración del principio de legalidad en la materia, se desprende lo que denominaremos facultad legislativa de configuración de la protección de la vida privada: esto es, si bien existe un mandato constitucional de protección de aquélla, ello ha de realizarse según las pautas que, democráticamente, decida el legislador: la Constitución lo obliga a proteger la vida privada, pero no a hacerlo de determinada manera. Ante ello, el TC señala que tampoco puede realizarlo "de cualquier manera", sino mediante el establecimiento de garantías de protección que deben ser adecuadas y suficientes. El contenido de aquello no ha sido desarrollado por su jurisprudencia aún, de manera que habrá que esperar futuros pronunciamientos para esclarecer el punto en esta sede.

\section{CONCLUSIONES}

De lo desarrollado se pueden concluir las siguientes ideas:

I. Nuestra jurisprudencia constitucional ha sido particularmente tardía en el reconocimiento de la relevancia constitucional de la protección de datos personales, mostrando una jurisprudencia poco sistemática y que no se hace cargo de las complejidades de la realidad que, actualmente, regula el artículo I9 nro. 4 de la Constitución.

2. Se han establecido un conjunto de estándares constitucionales que, si bien pueden no ser del todo sistemáticos y de la riqueza doctrinal esperable, constituyen criterios que, de seguro, se aplicarán cuando se planten casos relativos a la protección de datos personales ante esta magistratura. Dichos estándares son:

- Principio de legalidad en la protección de datos personales.

- Fundamento en la primacía axiológica del ser humano de la protección de datos personales y el libre desarrollo de la personalidad.

«Además, con detrimento de la seguridad jurídica, el proyecto presenta todos los vacíos a que se ha hecho mención respecto a la custodia e intangibilidad de los susodichos archivos, materia en que se remite globalmente y en blanco a un reglamento, vale decir, sin la debida protección legal que debe otorgarse a las personas para el ejercicio tranquilo de sus derechos (aplica sentencia rol nro. 370, considerando diecinueve)» (considerando veinticuatro). 
- Principio del consentimiento para la injerencia en la esfera amparada.

- Efecto horizontal de esta garantía.

- La protección de la vida privada no es un derecho absoluto y sus restricciones deben tener por fundamento un objetivo legítimo.

- Principio de no afectación a un bien jurídico superior.

- Protección constitucional de datos personales (datos sensibles) y su anclaje constitucional en la protección de la vida privada.

- Irrelevancia de la cualidad del ámbito espacial de desarrollo de la actividad libre amparada por el derecho.

- Principio de protección con garantías adecuadas y suficientes.

- Principio de no lesión de intereses sociales o derechos fundamentales

- Interdicción de seguimientos o monitoreos sistemáticos, constantes y focalizados.

Si bien el Tribunal Constitucional en un inicio, en la sentencia rol nro. 389-03, pudo haber iniciado el entendimiento de la protección a la vida privada como una libertad positiva, que permitiera dar el paso necesario para conceptualizar la protección de datos personales como un derecho de control sobre dicha información, ello no se materializa, por cuanto sucesivamente se señalará o entenderá como un derecho negativo. No obstante ello, en su segunda etapa reconoce el derecho de autodeterminación informativa y deja abierta la posibilidad de reentender la protección a la vida privada, lo cual denota una abierta contradicción pero que da luces de futuros avances en la materia.

\section{REFERENCIAS}

Barros Bourie, Enrique (I998). «Honra, privacidad e información: Un crucial conflicto de bienes jurídicos». Revista de Derecho (Universidad Católica del Norte), 5: 47.

Cate, Fred y Robert Litan (200I). Constitutional Issues in Information Privacy. Joint Center AEI-Brookings Joint Center For Regulatory Studies, Working paper OI-II. 
Cordero, Eduardo (2009). «El sentido actual del dominio legal y la potestad reglamentaria». Revista de Derecho (Pontificia Universidad Católica de Valparaíso), 32: 409-40.

Ferrajoli, Luigi (200I). Derecho y razón. Madrid: Trotta.

- (2007). Los fundamentos de los derechos fundamentales. Madrid: Trotta.

Murillo de la Cueva, Pablo Lucas (I979). «La construcción del derecho a la autodeterminación informativa». Revista de Estudios Políticos, 104: 35-63.

- (2007). «Perspectivas del derecho a la autodeterminación informativa». Revista de Internet, Derecho y Política, 5: I 8-32.

Nogueira, Humberto (2005). "Autodeterminación informativa y hábeas data en Chile e información comparativa». Anuario de Derecho Constitucional Latinoamericano, 2 (II): 449-47I.

Novoa Monreal, Eduardo (I98I). Derecho a la vida privada y libertad de información. México: Siglo XXI.

Pérez Luño, Antonio-Enrique (I979). «La protección de la intimidad frente a la informática en la Constitución Española de I978». Revista de Estudios Políticos, 9: 59-72.

Romero, Xiomara (2008). «El alcance del derecho a la intimidad en la sociedad actual». Revista Derecho del Estado, 2I: 209-222.

Rubenfeld, Jed (1989). «The Right of Privacy». Harvard Law Review, IO2 (49): 737-807.

SAARENPäÄ, Ahti (2003). «Europa y la protección de los datos personales». Revista Chilena de Derecho Informático, 3: I 5-29.

SALDAÑa, María Nieves (2007). "La protección de la privacidad en la sociedad tecnológica: el derecho constitucional a la privacidad de la información personal en los Estados Unidos». Revista Iberoamericana de Filosofía, Política y Humanidades, I 8: 85-I I 5.

SCHWAVE, Jürgen (2009). Jurisprudencia del Tribunal Constitucional Federal Alemán. México: Konrad Adenauer Stifting, Programa Estado de Derecho para América Latina.

Serrano, María Mercedes (2005). «El derecho fundamental a la protección de datos. Su contenido esencial». Nuevas politicas públicas. Anuario multidisciplinar para la modernización de las administraciones públicas, I: 245-265. 
Solove, Daniel (2006). «A Taxonomy of Privacy». University of Pennsylvania Law Review, I 54 (3): 477-560.

ZúÑIGA, Francisco (200I). «Apostillas: Ley y reglamento en la Jurisprudencia del Tribunal Constitucional (de la germanización al practicismo)». Revista Ius et Praxis, 7 (2): 209-257.

Vivanco, Ángela (2006). Curso de Derecho Constitucional. Tomo II. Santiago: Ediciones Universidad Católica de Chile.

\section{SOBRE EL AUTOR}

Flavio Quezada Rodríguez es profesor de Derecho Administrativo de la Facultad de Derecho de la Universidad de Valparaíso. Abogado, Licenciado en Ciencias Jurídicas y Sociales por la Universidad de Chile. Egresado del Magíster en Derecho, mención Derecho Público, de la Universidad de Chile. Asociado de Aninat, Schwencke \& Cía. Contacto: <flavioqr@gmail.com> o <fquezada@asyc.com>. El presente artículo es una versión mejorada de la investigación realizada para el seminario sobre «Datos personales», dictada por el profesor Alberto Cerda Silva, en el programa del Magister en Derecho de la Universidad de Chile. El autor agredcece los trascendentales comentarios que el profesor Cerda hiciera para su mejora, a la hora de corregirlo, al igual que lo pertinentemente indicado por Felipe Peroti y el profesor José Roa.

Este trabajo fue recibido el 2 de enero de $20 \mathrm{I} 2$ y aprobado el 22 de junio de 20 I2. 
